\title{
A computer form to aid in the collection of data on the ocular complications of leprosy
}

\author{
T J FFYTCHE \\ St Thomas' Hospital, London
}

Accepted for publication 23 February 1983

\begin{abstract}
Summary. There is a need for data on the wide variety of ocular complications of leprosy that have been observed in patients in different parts of the world. Such data would be valuable in the planning of eye care and preventive measures. A computer form has been designed to collect information from groups of leprosy patients so that the results can be centralized and submitted for analysis. The form can be used by medical students as well as medical and para-medical workers, and guidelines on ophthalmic examination in leprosy and the recording of the findings are presented.
\end{abstract}

\section{Introduction}

Information on the ocular complications of leprosy remains incomplete and often anecdotal, and yet visual impairment is one of the major features of the disease. Vision plays an important role in the health and well-being of leprosy patients, its preservation may decrease the severity of the disabilities that typify the advanced condition and its loss imposes a harsh burden, isolating the individual and greatly diminishing the quality of life.

It is becoming increasingly apparent that many of the complications that affect the eyes in leprosy are potentially preventable if they are diagnosed and treated early enough, and health care directed towards these aspects would alleviate much suffering and incapacity. One of the main difficulties in assessing ocular damage from leprosy is the wide variation in the manifestations of eye disease in different parts of the world. Ocular involvement depends on a number of known factors such as the type of leprosy, its status, duration and therapy, and on several less-understood factors including the race and occupation of the patient and the locality and climate of the environment. Reports from different areas of the world emphasize the wide spectrum of ocular leprosy, high-lighting regional variations; and the few statistics to emerge are difficult to interpret. If preventive ophthalmic care is to be successful it is important to determine the 
geographic and regional differences in ocular involvement so that leprosy populations at risk can be identified. A computer form has been designed in order to record a number of parameters in groups of patients so that variations of ocular manifestations can be analysed according to factors known or suspected to be influential. By centralizing this data, patterns of ocular disease can be determined and fitted into the mosaic of existing knowledge of the global distribution of leprosy.

\section{Data collection}

The ocular complications are usually confined to the anterior segment of the eye and are therefore visible to an examiner using basic equipment of direct illumination and some form of magnification. The slit-lamp and ophthalmoscope are, of course, valuable instruments and give more specialized information, but they require an observer skilled not only in their use but also in the interpretation of what they display. A survey has been set up which is designed to provide data on the gross ocular changes that occur in leprosy without the necessity for the examiner to have detailed ophthalmic knowledge. Observations are recorded on a proforma which can be used by informed para-medical workers and medical students as well as doctors, and it has already been shown by the Peace Corps Survey in South Korea that intelligent observers without formal medical training can provide valuable statistical information on ocular complications by this means.'

The proforma is demonstrated in Figure 1 and consists of a questionnaire recording 35 factors for each patient examined. The findings are coded numerically so that they can be transferred easily to a computer. The key to the proforma is tabulated (Figure 2). In any situation where a number of different individuals are assessing ocular findings there is bound to be much variation in the interpretation and recording of clinical signs. This depends not only on the skill and ophthalmic experience of the examiner, but on other factors such as the available equipment and the communication and cooperation of the patients. An attempt should be made to standardize the examination procedures and the following guidelines are suggested to assist in completing the proforma.

\section{Guidelines}

It should be possible to re-study patients at intervals and for this reason all patients should be given a reference number consisting of two letters to denote the country where the survey is being carried out (e.g. 'NE' for Nepal) and 4 numbers to identify the patient. This reference should be catalogued with the patient's name and address. 


\begin{tabular}{|c|c|c|c|c|}
\hline \multirow{2}{*}{$\begin{array}{l}\text { REF : } \\
\text { RACE : }\end{array}$} & \multicolumn{3}{|c|}{ DATE: } & SEX: \\
\hline & \multicolumn{2}{|c|}{ OCC: } & LOC: & CLIM: \\
\hline TYPE: & \multicolumn{2}{|c|}{ DUR: } & STAT: & TREAT: \\
\hline \multicolumn{2}{|l|}{ VA } & $\mathrm{R}:$ & L: & BROWS : \\
\hline \multicolumn{2}{|l|}{ LIDS } & $\mathrm{R}:$ & L: & TRICH : \\
\hline \multicolumn{2}{|c|}{ CLOSURE : } & TARS: & \multicolumn{2}{|c|}{ LAC: } \\
\hline SCLERA & & $\mathrm{R}:$ & L: & CONJ: \\
\hline \multirow[t]{2}{*}{ CORNEA } & OPAC & $\mathrm{R}:$ & L: & PTY : \\
\hline & SENS & $\mathrm{R}:$ & L: & NERVES: \\
\hline \multirow[t]{3}{*}{ PUPIL } & REACT & $\mathrm{R}:$ & $\mathrm{L}:$ & \\
\hline & SIZE & $\mathrm{R}:$ & L: & \\
\hline & SHAPE & $\mathrm{R}:$ & L: & SYN : \\
\hline \multicolumn{2}{|l|}{ IRIS } & $\mathrm{R}:$ & L: & PEARLS : \\
\hline \multicolumn{2}{|l|}{ LENS } & $\mathrm{R}:$ & L: & \\
\hline \multicolumn{2}{|c|}{ BLINDNESS } & $\mathrm{R}:$ & L: & \\
\hline \multicolumn{2}{|c|}{ HAND MOB } & $\mathrm{R}:$ & L: & \\
\hline \multicolumn{2}{|c|}{ FINGERS } & $\mathrm{R}:$ & L: & \\
\hline
\end{tabular}

Figure 1. Proforma for recording data.

In the subsequent sections an attempt has been made to provide data on environmental and occupational factors that may be relevant in the pathogenesis of ocular complications. Details of the type of leprosy, its duration, status and therapy should also be recorded, if possible from case notes or by direct questioning. When data are not available an ' $\mathrm{X}$ ' should be entered onto the proforma.

\section{OCULAR EXAMINATION}

It would be difficult to produce a comprehensive form that covered every possible ocular complication of leprosy, but conditions frequently associated with the disease have been listed and, with the exception of visual acuity measurements, all 
Al l unknowns write' $X$ '

REForince: NE 0687

\section{RACE :}

$\begin{array}{ll}\text { African } & 1 \\ \text { Arab } & 2 \\ \text { Asian } & 3 \\ \text { Chinese } & 4 \\ \text { European } & 5 \\ \text { Indian } & 6 \\ \text { S America } & 7 \\ \text { Mixed } & 8 \\ \text { Others } & 9\end{array}$

TYPE of leprosy:

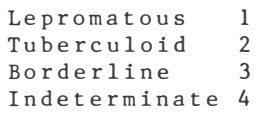

\section{$\underline{\mathrm{VA}}$ :}

$\begin{array}{ll}\text { NPL } & 1 \\ \text { PL } & 2 \\ \text { HM } & 3 \\ \text { CF } & 4 \\ 3 / 60 & 5 \\ 6 / 60 & 6 \\ 6 / 36 & 7 \\ 6 / 24 & 8 \\ 6 / 18 & 9 \\ 6 / 12 & 10 \\ 6 / 9 & 11 \\ 6 / 6 & 12\end{array}$

CLOSure:

\section{Norma 1}

Inadequate $R$

Inadequate $\mathrm{L}$

Inadequate $\mathrm{R}+\mathrm{L} \quad 4$

\section{SCLERA :}

$\begin{array}{ll}\text { Normal } & 1 \\ \text { Nodules } & 2 \\ \text { Plaques } & 3 \\ \text { Episcleritis } & 4 \\ \text { Scleritis } & 5 \\ \text { Staphyloma } & 6 \\ \text { Others } & 7\end{array}$

DATE: $1153(=$ Nov 1953) SEX: male 1 female 2 AGE: in years

OCCupation:

$\begin{array}{ll}\text { Agriculture } & 1 \\ \text { Labourer } & 2 \\ \text { Fisherman } & 3 \\ \text { Factory } & 4 \\ \text { Professional } & 5 \\ \text { Clerical } & 6 \\ \text { School } & 7 \\ \text { Home } & 8 \\ \text { Others } & 9\end{array}$

DURation :

in years

\section{BROWS :}

Norma 1

Reduced

Absent

Transplant
TARSorrhaphy:

$\begin{array}{ll}\text { Absent } & 1 \\ \text { Right } & 2 \\ \text { Left } & 3 \\ \text { Bilateral } & 4\end{array}$

\section{I D :}

Norma 1

Ectropion

Lagopht halmos

Entropion

Temp transfer

Others
CLIMate:

$\begin{array}{ll}\text { Wet tropical } & 1 \\ \text { Dry tropical } & 2 \\ \text { Warm temperate } & 3 \\ \text { Cool temperate } & 4 \\ \text { Cold } & 5 \\ \text { Others } & 6\end{array}$

TREATment :

Sulphones

Chaulmoogra

Rifampicin

Lamprene 4

Steroids 5

Combined $1-4 \quad 6$

Combined $1-5 \quad 7$

Others 8

None

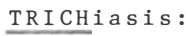

$\begin{array}{ll}\text { Absent } & 1 \\ \text { Right } & 2 \\ \text { Left } & 3 \\ \text { Bilateral } & 4\end{array}$

LACrima 1 :

$\begin{array}{ll}\text { Normal } & 1 \\ \text { Blockage R } & 2 \\ \text { Blockage L } & 3 \\ \text { Dacryocystitis } & 4\end{array}$

CONJunctiva :

Figure 2, part 1

normal findings are designated by the number ' 1 '. In the event of more than one condition being present within a section, the complication most likely to cause visual loss should be recorded and a comment on the second factor made at the end of the proforma. 


\section{CORNEA OPACities:}

$\begin{array}{ll}\text { Absent } & 1 \\ \text { Pannus } & 2 \\ \text { Mild } & 3 \\ \text { Moderate } & 4 \\ \text { Severe } & 5 \\ \text { Total } & 6 \\ \text { Leproma } & 7\end{array}$

PUPIL REACTions:

$\begin{array}{ll}\text { Normal } & 1 \\ \text { Diminished } & 2 \\ \text { Absent } & 3\end{array}$

Absent

\section{IRIS :}

\section{Norma 1}

Atrophy

Floccules

Floccules + atr.

Acute iritis

Chronic iritis

Leproma

others

HAND MOBility:

\section{PUPIL SIZE :}

$\begin{array}{ll}2-4 \mathrm{~mm} & 1 \\ <2 \mathrm{~mm} & 2 \\ >4 \mathrm{~mm} & 3 \\ \text { Iridectomy } & 4 \\ \text { Seclusio } & 5\end{array}$

\section{PEARLS :}

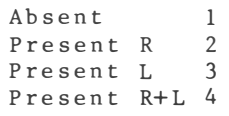

CORNEA SENSation:

Norma 1

Diminished

Absent
CORNEA NERVES:

$\begin{array}{lll}\text { Not seen } & & 1 \\ \text { Thickened } & R & 2 \\ \text { Thickened } & \text { L } & 3 \\ \text { Thickened } & \text { R+L } & 4\end{array}$

SYNechiae:

$\begin{array}{ll}\text { Normal } & 1 \\ \text { Irregular } & 2 \\ \text { Eccentric } & 3 \\ \text { Multiple } & 4 \\ \text { Iridectomy } & 5\end{array}$

LENS:

Norma 1

Mild cataract

Dense cataract

Aphakia $\begin{array}{lll}\text { Absent } & & 1 \\ \text { Present } & R & 2 \\ \text { Present } & L & 3 \\ \text { Present } & R+L & 4\end{array}$

BLINDNESS (cause):

\section{Norma 1}

mild reduction

Moderate reduction

No function

\section{FINGERS :}

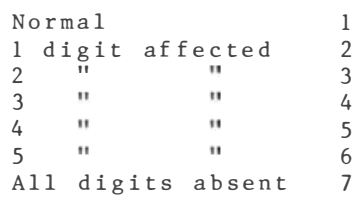

$6 / 60$ or better

Corneal opacity

Chronic iritis

Seclusio

Cataract

Staphyloma

$\mathrm{Phth}$ is is

Absent eye

Others

Cataract + iritis 12

Cataract + cornea + iritis

COMMENTS :

Anything of particular interest not included in the above.

Figure 2, part 2. Key to data form.

\section{VISUAL ACUITY (VA)}

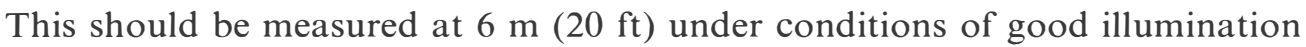
using standard E test-types. Each eye should be assessed separately and the best visual acuity recorded with glasses if worn. Patients with sub-normal vision should be tested with a pin-hole aperture.

\section{BROWS}

Partial or complete loss of both eyebrows together should be recorded and the presence of eyebrow transplants noted.

LIDS

Ectropion refers to eversion of the lower lid margin without impairment of lid 
closure or blinking. Lagophthalmos is present when there is inability to close the lids completely leaving some of the cornea exposed; it implies facial nerve palsy and is associated with loss of normal blinking and the protective blink reflex. The combination of lagophthalmos and impairment of corneal sensation is a potent cause of corneal scarring and blindness in leprosy. Entropion is present when the lid is inverted and is often associated with troublesome trichiasis. The presence of a temporalis transfer operation should be noted.

\section{TRICHIASIS}

The presence of lashes in the upper or lower lids which rub against the cornea should be recorded - the condition may give rise to corneal scarring.

\section{CLOSURE}

A facial nerve palsy is an important complication of all forms of leprosy requiring surgical attention if the health and transparency of the cornea cannot be maintained by medical means. It should be assessed by asking the patient to close the eyes and observing whether the cornea is adequately covered. Closure against resistance is diminished in early cases.

\section{TARSORR HA PHY}

The presence of lateral or medial tarsorrhaphies in either eye should be noted.

\section{LACRIMAL}

Disturbances of the lacrimal passages are not a common feature of leprosy but may occur when there is extensive nasal destruction. Watering caused by blockage of the tear ducts should be recorded as it may encourage secondary corneal infection. Occasionally a chronic dacryocystitis is present with swelling at the root of the nose, and a purulent regurgitation into the conjunctival sac may be produced by pressure on the swelling.

\section{SCLERA}

Leprosy may cause nodules to develop astride the corneo-scleral margin and these should be distinguished from the more common pterygium. Flat plaques consisting of discrete areas of tissue swelling often greyish in colour may also occur but are rare. Episcleritis and scleritis are seen in the disease and should be distinguished. In episcleritis there is superficial redness with a localized engorgement of blood vessels. The redness in scleritis by contrast is deep and more diffuse causing considerable pain and local tenderness. A staphyloma (a localized 
dehiscence of the sclera) is associated with gross scleral thinning often following scleritis and carries a poor prognosis frequently progressing to phthisis bulbi (shrunken eye).

\section{CONJUNCTIVA}

Inflammation of the conjunctiva is rarely caused by leprosy itself but occurs in diseases such as trachoma or may represent secondary infection.

\section{CORNEAL OPACITIES}

With the exception of pannus and corneal leproma no attempt need be made to distinguish the many types of corneal opacity that may complicate all forms of leprosy. In most cases corneal scarring is secondary to chronic exposure or trichiasis, although a primary keratitis occurs in lepromatous leprosy. Pannus occurs in leprosy in the form of a peripheral opacity, often vascularized, which extends around the whole circumference of the cornea, and its affect on vision is negligible. All other types of corneal scarring should be graded according to their effect on visual acuity: mild scarring refers to those cases where the scars do not obstruct the vision at all; in moderate scarring vision is affected but it is possible to see details of the underlying structures adequately through the scars; in severe scarring there is obviously considerable visual impairment and iris details are almost completely obscured. Total corneal opacity should be recorded when no details are visible through the scar and the condition is usually associated with vision reduced to bare perception of light. A corneal leproma is a rare tumour-like lesion which may extend across the cornea from the sclera.

\section{PTER YGIUM}

Pterygium is common in many parts of the world especially in those who work out of doors in a hot dusty environment. The presence of pterygium, although no more frequent in leprosy, may indicate those patients whose occupations predispose to recurrent minor ocular irritation and trauma which would be harmful for eyes with corneal anaesthesia or facial palsy.

\section{CORNEAL SENSATION}

Diminished or absent corneal sensation is an important ocular complication since it renders the cornea more susceptible to damage from external factors. It should be tested by touching the centre of the cornea with a wisp of cotton wool and observing the blink reflex, or in those patients with facial palsy by asking whether the stimulus was felt. 


\section{CORNEAL NER VES}

Thickened corneal nerves are a pathognomonic sign of lepromatous leprosy. They appear as white lines extending towards the centre of the cornea from the edge and they may show localized swelling resembling a string of beads. They are a transient phenomenon occurring relatively early in the disease.

\section{PUPIL REACTIONS}

Chronic iritis is an important cause of blindness in lepromatous leprosy and is often associated with cataract. One of the early signs is a diminution or loss of the pupil reactions to light, particularly the recovery phase of the light reflex. The test should be carried out in a darkened room or in the shade.

\section{PUPIL SIZE}

Chronic iritis also causes increasing miosis resulting eventually in a pin-point pupil which does not respond to conventional dilating drops. Vision is considerably impaired through these small pupils especially if there are additional corneal or lens opacities. The pupil size should be measured in subdued light with the patient facing away from any bright illumination. In cases who have had previous ocular surgery a broad iridectomy may be present so that no assessment of size can be made and this should be recorded. In advanced cases especially those in whom acute iritis has occurred previously, the pupil may be bound down with organized exudate which fills the pupil aperture - this condition is known as seclusio pupillae and is usually associated with profound visual impairment.

\section{PUPIL SHAPE}

Chronic iritis may also produce abnormalities of pupil shape and position and in some cases advanced iris atrophy can give rise to multiple apertures. Small peripheral iridectomies may be present in eyes that have had surgery for cataract or glaucoma.

\section{SYNECHIAE}

Adhesions between the iris and lens (synechiae) usually indicate a past history of acute iritis although they are sometimes seen in chronic iritis. Their presence is often difficult to detect especially when the pupil is small, but they should be suspected if there are irregularities of the pupil margin or if the light reaction is unequal in different quadrants of the iris. 
IRIS

The most common feature of the chronic iritis of lepromatous leprosy is a progressive atrophy of iris tissue culminating in a loss of all iris mobility and a miotic pupil. Iris patterns vary according to race and age but atrophy is characterized by loss of the normal iris landmarks and degeneration of the stroma exposing the underlying pigment epithelium or even the lens. The pupil margin itself may become ragged. In some races whitish deposits may occur at the pupil margin in patients with chronic iritis and lie on the surface of the lens - these are known as floccules and they may occur independently or more commonly in association with iris atrophy.

An acute iritis may occur in all types of leprosy, particularly the intermediate forms when a change in polarity is taking place, and it may be provoked by alterations in treatment. The clinical signs are characteristic of all forms of acute iritis with pain, redness and visual loss with the formation of synechiae. Patients with acute iritis require urgent treatment with local mydriatic and steroid drops.

Chronic iritis is difficult to detect without a slit-lamp and its presence must often be inferred. Turbidity of the aqueous in the anterior chamber may be visible and the presence of keratic precipitates $(\mathrm{kp})$ on the posterior surf ace of the cornea is also indicative of the condition. Eyes with chronic iritis usually show very little evidence of inflammation with minimal or no redness and hardly any discomfort. A diagnosis of chronic iritis, therefore, must take a number of different signs into consideration, these include the pupil size, shape and reactions together with its appearance and the presence of iris pearls and synechiae. Single white lesions may occur on the iris in some races but these lepromas are rare.

\section{PEARLS}

Iris pearls collecting near the pupil margin or in the periphery of the iris are also pathognomonic for lepromatous leprosy and may occur during the early stages of chronic iritis. Like thickened corneal nerves they are a transient phenomenon as they eventually detach from the iris and become absorbed. When present in large numbers they may form a solid white mass in the lower part of the anterior chamber resembling a hypopyon but without any obvious inflammatory signs.

\section{LENS}

Cataract is a common cause of blindness in all parts of the world and occurs in the older age groups. Many leprosy patients live to a good age and it is therefore very difficult to decide whether a patient with cataract has developed the condition because of the disease or due to normal senile changes. The detection of cataract may be difficult particularly if the pupil is small but it is usually possible to observe superficial lens opacities. 


\section{Surveys}

It is intended that the proforma should be used in a number of surveys carried out in areas of the world chosen for their environmental and climatic differences. Initial studies are already being carried out in Nepal, Thailand, India and Kenya by medical students from St Thomas' Hospital and St George's Hospital, London. Each survey should aim to examine at least 100 leprosy patients, preferably those who have been registered with local health authorities so that information on the duration, status and therapy of the disease can be obtained. The students are encouraged to examine a broad spectrum of the leprosy community, not just those with eye complaints - indeed the identification of leprosy patients not affected ocularly is equally important for the analysis. The selection of this representative sample of patients to be studied is of fundamental

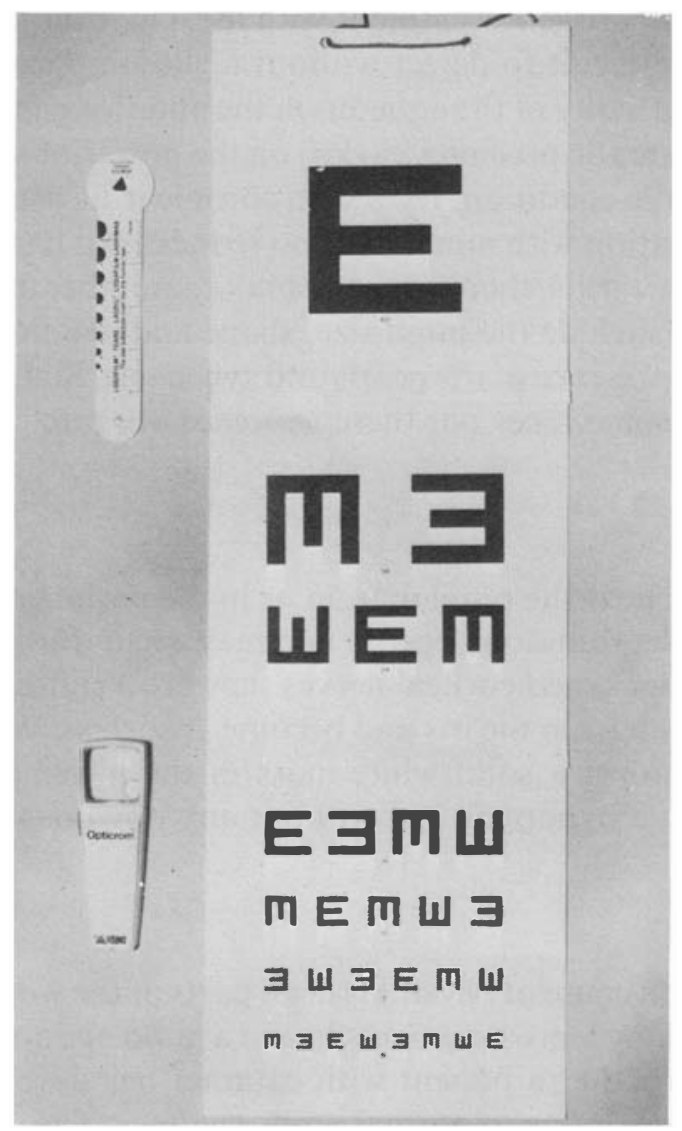

Figure 3. Basic equipment. Folding E test-type (Keeler Instruments Limited). Illuminated loupe (Fisons). Optistick with pin-hole (Allergan). 
importance and every attempt should be made to avoid bias towards patients with ocular complications. Studies are therefore preferred in resettlement communities rather than in established leprosaria where the more chronic and disabled cases tend to remain, many of whom have advanced ocular problems. It is of course realized that these criteria for patient selection may not be possible.

The students are provided with basic equipment consisting of a folding $\mathrm{E}$ test-type, an illuminated loupe and a pin-hole aperture which also incorporates a scale for measuring pupil size (Figure 3).

The results of the surveys will be entered onto the Iris Fund computer at St Thomas' Hospital, London where an analysis and interpretation can be carried out. From this accumulated evidence it is hoped that information can be derived on the way leprosy affects the eyes in different populations in various parts of the world so that training programmes in eye care for health workers and doctors can be modified to take into account the locality of their work. It is also intended that the information will provide a basis for longitudinal studies on groups of patients in order to gain more data on the natural history of ocular complications.

\section{Acknowledgments}

This work was stimulated by visits to the Wilson Leprosy Centre, Suncheon, South Korea and is based on experience gained from the Peace Corps Survey on the ocular complications in leprosy in that country. I am grateful to LEPRA for financial assistance, to the Iris Fund at St Thomas' Hospital for computer facilities and for the help of Dr Andrew Plumb in developing the computer program. Equipment for the student leprosy surveys was donated by Keeler Instruments Limited, Fisons and Allergan. I would like also to thank Mrs Lesley Gibbons for secretarial help.

\section{Reference}

1 Courtright P, Green R, Pilarski R, Smucny J. A survey of the eye complications of leprosy in South Korea. Lepr Rev, 1984; 55 (in press). 